\title{
Fetal echogenic gut: a marker of intrauterine gut ischaemia?
}

\author{
A K Ewer, J M McHugo, S Chapman, S J Newell
}

\begin{abstract}
The pathophysiological significance of fetal echogenic gut (FEG) is unknown. Our aim was prospectively to evaluate FEG in infants with intrauterine growth retardation (IUGR) and absent umbilical artery end diastolic flow velocities. Over a 15 month period, nine infants with FEG met these criteria. Nine infants who, on antenatal assessment, had demonstrated IURG and absent umbilical artery end diastolic flow velocities, but no evidence of FEG, were selected as case-controls. Gastrointestinal function was then prospectively evaluated in both groups after delivery.
\end{abstract}

All liveborn infants received nasogastric feeds of breast milk by 8 days of age. All in the FEG group developed marked abdominal distension, large, bile stained, nasogastric aspirates, and constipation requiring rectal washouts. This led to a discontinuation of enteral feeds on one or more occasions. Two patients in the FEG group required water soluble contrast enemas in order to relieve intestinal obstruction. In the control group, 3/9 patients had abdominal distension, but no rectal washouts were given and enteral feeds were not interrupted. The median (range) time to tolerate full enteral feeds was 15 (7-32) days in the FEG group, compared with 4 (1-8) days in the control group. In the FEG group $5 / 6$ patients required parenteral nutrition for 5-27 days. In the control group one patient required parenteral nutrition over a period of four days only. No child had necrotising enterocolitis or cystic fibrosis.
When FEG is observed in the fetus with IUGR, problems with enteral feeding should be anticipated.

(Arch Dis Child 1993; 69: 510-513)

Fetal assessment is providing an increasing amount of information about preterm infants before they arrive on the neonatal intensive care unit. The finding of hyperechogenic gut on antenatal ultrasound has been described previously. Intra-abdominal calcification and echogenic ascites secondary to meconium peritonitis are well documented, ${ }^{1}$ and Blott et al described hyperechogenic gut in eight fetuses who subsequently developed obstruction due to meconium without intestinal perforation. ${ }^{2}$ In this study FEG was defined as a generalised increase in the echogenicity of the bowel, without evidence of ascites, in a fetus who is otherwise structurally normal.

During detailed assessment of 'at risk' fetuses we have observed hyperechogenic or 'bright' gut (FEG) on ultrasound scan in a number of growth retarded fetuses with absent umbilical artery end diastolic flow velocities. ${ }^{3}$ In the growth retarded infant with abnormal antenatal Doppler studies, an increased incidence of necrotising enterocolitis has been demonstrated. ${ }^{45}$ It is possible that regional redistribution of blood flow may lead to chronic hypoperfusion of the gut and the echogenicity noted may be a marker of this phenomenon. We therefore hypothesised that the gastrointestinal function may be affected in infants who demonstrated FEG. The aim of this study was prospectively to evaluate gastrointestinal function in patients with FEG and matched case controls.

Patients and methods

FEG was detected on antenatal ultrasound and was defined as an abnormally bright area of bowel which had a similar echogenicity to the fetal vertebral body (fig 1). Over a 17 month period at Birmingham Maternity Hospital, during ultrasonic assessment of high risk pregnancies, fetuses with intrauterine growth retardation (IUGR, defined as abdominal circumference less than the 5 th centile on one or more occasions), and absent umbilical artery end diastolic flow velocities on Doppler ultrasound, were examined for the presence of FEG. Fetal ultrasonography, Doppler studies, and assessment of gut echogenicity were all performed by the same observer (JMM). Nine fetuses with FEG were identified, in whom this was the only ultrasonic abnormality. FEG was
Figure 1 Two ultrasound images from the same fetus. $(A)$ The normal ultrasonic appearance of the fetal abdomen. (B) Three weeks later showing the presence of FEG. The abnormally bright area of bowel is arrowed; $V$ : vertebral body, F: femur. 
Table 1 Clinical characteristics of infants with FEG

\begin{tabular}{|c|c|c|c|c|c|c|c|}
\hline $\begin{array}{l}\text { Gestation } \\
\text { (weeks) }\end{array}$ & Sex & $\begin{array}{l}\text { Birth } \\
\text { weight } \\
\text { (g) }\end{array}$ & $\begin{array}{l}\text { Head } \\
\text { circumference } \\
\text { (cm) }\end{array}$ & $\begin{array}{l}\text { Birthweight } \\
\text { SD score } \\
\text { (SD) }\end{array}$ & Outcome & $\begin{array}{l}\text { IPPV } \\
\text { (days) }\end{array}$ & $\begin{array}{l}\text { Maternal } \\
\text { factors }\end{array}$ \\
\hline $\begin{array}{l}29 \\
29\end{array}$ & $\begin{array}{l}\mathbf{M} \\
\mathbf{M}\end{array}$ & $\begin{array}{r}1160 \\
620\end{array}$ & $\begin{array}{l}28 \cdot 5 \\
22 \cdot 0\end{array}$ & $\begin{array}{l}-0.77 \\
-3.74\end{array}$ & $\begin{array}{l}\text { Alive } \\
\text { Alive }\end{array}$ & $\begin{array}{r}7 \\
18\end{array}$ & $\begin{array}{l}\text { Pre-eclampsia } \\
\text { Abnormal } \\
\text { cardiotocograph }\end{array}$ \\
\hline $\begin{array}{l}35 \\
30\end{array}$ & $\begin{array}{l}F \\
F\end{array}$ & $\begin{array}{l}770 \\
810\end{array}$ & $\begin{array}{l}25 \cdot 1 \\
24 \cdot 5\end{array}$ & $\begin{array}{l}-3 \cdot 84 \\
-2 \cdot 70\end{array}$ & $\begin{array}{l}\text { Alive } \\
\text { Alive }\end{array}$ & $\begin{array}{l}0 \\
0\end{array}$ & $\begin{array}{l}\text { Abnormal } \\
\text { cardiotocograph }\end{array}$ \\
\hline $\begin{array}{l}29 \\
30 \\
29\end{array}$ & $\begin{array}{l}F \\
F \\
M\end{array}$ & $\begin{array}{l}640 \\
900 \\
770\end{array}$ & $\begin{array}{l}24 \cdot 5 \\
25 \cdot 5 \\
25 \cdot 0\end{array}$ & $\begin{array}{l}-3.63 \\
-2.34 \\
-2.91\end{array}$ & $\begin{array}{l}\text { Stillborn } \\
\text { Stillborn } \\
\text { Alive }\end{array}$ & $\overline{-}$ & $\begin{array}{l}\text { Oligohydramnios } \\
\text { Abnormal } \\
\text { cardiotocograph }\end{array}$ \\
\hline $\begin{array}{l}32 \\
28\end{array}$ & $\begin{array}{l}\mathbf{M} \\
\mathbf{F}\end{array}$ & $\begin{array}{l}790 \\
640\end{array}$ & $\begin{array}{l}25 \cdot 0 \\
21 \cdot 0\end{array}$ & $\begin{array}{l}-4 \cdot 43 \\
-3 \cdot 12\end{array}$ & $\begin{array}{l}\text { Alive } \\
\text { Stillborn }\end{array}$ & $\begin{array}{l}0 \\
-\end{array}$ & \\
\hline
\end{tabular}

IPPV: intermittent positive pressure ventilation.

first detected at between 18 and 30 weeks' gestation. The precise timing of the onset of FEG was difficult to evaluate in all patients because several were transferred from other centres late in pregnancy for further assessment.

FEG was noted consistently in four patients on at least two occasions. In two of these patients it was demonstrated at 18 weeks and persisted until delivery at 29 and 35 weeks. In the other two FEG was first seen at 21 and 27 weeks and persisted until 24 and 29 weeks' gestation respectively. Among the remaining five patients, it was observed one week before delivery in two, and in three cases on the day of delivery during the first scan at Birmingham Maternity Hospital after in utero transfer.

Once noted FEG did not resolve in any of the patients and clinical data were then recorded prospectively on each infant following delivery (table 1). Three of the FEG group were stillborn and postmortem examination was performed in each case. Each infant with FEG was then matched for gestational age and birth weight with the next consecutively available infant who fulfilled the entry criteria: IUGR as defined above, and absent umbilical artery end diastolic flow velocities (table 2). None of the case controls had FEG. There was no significant difference between the two groups in gestation, birth weight, head circumference, birthweight SD score, or sex ratio (Mann-Whitney U analysis).

Gastrointestinal function was evaluated in each infant according to the following criteria: presence of abdominal distension, delay or difficulty in the passage of meconium, time to full enteral feeds, and necessity for parenteral nutrition.

Table 2 Clinical characteristics of case-control infants

\begin{tabular}{|c|c|c|c|c|c|c|c|}
\hline $\begin{array}{l}\text { Gestation } \\
\text { (weeks) }\end{array}$ & Sex & $\begin{array}{l}\text { Birth } \\
\text { weight } \\
\text { (g) }\end{array}$ & $\begin{array}{l}\text { Head } \\
\text { circumference } \\
(\mathrm{cm})\end{array}$ & $\begin{array}{l}\text { Birthweight } \\
\text { SD score } \\
\text { (SD) }\end{array}$ & Outcome & $\begin{array}{l}\text { IPPV } \\
\text { (days) }\end{array}$ & $\begin{array}{l}\text { Maternal } \\
\text { factors }\end{array}$ \\
\hline $\begin{array}{l}32 \\
31 \\
32\end{array}$ & $\begin{array}{l}\mathbf{M} \\
\mathbf{M} \\
\mathbf{F}\end{array}$ & $\begin{array}{r}1465 \\
765 \\
700\end{array}$ & $\begin{array}{l}29 \cdot 0 \\
24 \cdot 0 \\
24 \cdot 0\end{array}$ & $\begin{array}{l}-1 \cdot 78 \\
-3 \cdot 01 \\
-4 \cdot 78\end{array}$ & $\begin{array}{l}\text { Alive } \\
\text { Alive } \\
\text { Alive }\end{array}$ & $\begin{array}{l}0 \\
0 \\
2\end{array}$ & $\begin{array}{l}\text { Pre-eclampsia } \\
\text { Abnormal } \\
\text { cardiotocograph }\end{array}$ \\
\hline $\begin{array}{l}31 \\
31\end{array}$ & $\begin{array}{l}\mathbf{M} \\
\mathbf{F}\end{array}$ & $\begin{array}{l}935 \\
545\end{array}$ & $\begin{array}{l}25 \cdot 0 \\
22 \cdot 3\end{array}$ & $\begin{array}{l}-2 \cdot 46 \\
-3 \cdot 71\end{array}$ & $\begin{array}{l}\text { Alive } \\
\text { Neonatal } \\
\text { death }\end{array}$ & $\begin{array}{l}0 \\
8\end{array}$ & $\begin{array}{l}\text { Cardiotocograpn } \\
\text { Pre-eclampsia }\end{array}$ \\
\hline $\begin{array}{l}31 \\
29\end{array}$ & $\begin{array}{l}\mathbf{F} \\
\mathbf{M}\end{array}$ & $\begin{array}{r}1240 \\
925\end{array}$ & $\begin{array}{l}28 \cdot 0 \\
26 \cdot 0\end{array}$ & $\begin{array}{l}-1 \cdot 48 \\
-2.06\end{array}$ & $\begin{array}{l}\text { Alive } \\
\text { Alive }\end{array}$ & $\begin{array}{l}0 \\
4\end{array}$ & $\begin{array}{l}\text { Abnormal } \\
\text { cardiotocograph }\end{array}$ \\
\hline $\begin{array}{l}36 \\
28\end{array}$ & $\begin{array}{l}\mathbf{F} \\
\mathbf{M}\end{array}$ & $\begin{array}{r}1610 \\
880\end{array}$ & $\begin{array}{l}31 \cdot 0 \\
26 \cdot 0\end{array}$ & $\begin{array}{l}-2.42 \\
-1.56\end{array}$ & $\begin{array}{l}\text { Alive } \\
\text { Alive }\end{array}$ & $\begin{array}{r}0 \\
10\end{array}$ & $\begin{array}{l}\text { Pre-eclampsia } \\
\text { Abnormal } \\
\text { cardiotocograph }\end{array}$ \\
\hline
\end{tabular}

IPPV: intermittent positive pressure ventilation.

\section{Results}

Three patients with FEG were stillborn and detailed postmortem examination performed by the regional perinatal pathologist revealed no abnormality, other than maceration, in the gastrointestinal tract. One infant in the control group died at 8 days of age from intracranial haemorrhage. All liveborn infants were small for gestational age. Three infants from the FEG group and four from the control group required mechanical ventilation, but none had severe lung disease (tables 1 and 2).

All infants received, in the first instance, expressed breast milk as hourly bolus nasogastric feeds and there was no significant difference between the two groups in the timing of the introduction of feeds. In all six surviving infants in the FEG group, difficulties were encountered introducing enteral feeds. Milk was introduced at a median of 2 days of age with a range of 1-8 days. All six infants were noted by nursing staff to develop marked abdominal distension and large, bile stained, nasogastric aspirates (greater than $80 \%$ of the total feed given over the previous four hours) or vomits were obtained shortly after introduction of feeds. This resulted in discontinuation of feeds for a minimum of 24 hours on at least one occasion in each case; feeds were discontinued on two occasions in three infants and on three occasions in one infant.

There was difficulty or a delay passing meconium in all infants with FEG. Although three patients in this group passed meconium within 24 hours of birth, two of the three required glycerine suppositories in order to achieve this. In three patients, meconium passage was delayed beyond 24 hours $(25,43$, and 90 hours), and glycerine suppositories were again required. Despite the subsequent administration of suppositories to all six infants with FEG, this resulted in the passage of small amounts of meconium only, which was insufficient to relieve the abdominal distension. All infants went on to receive saline or acetylcysteine rectal washouts at intervals of six hours. In four infants this was sufficient and was followed by adequate passage of meconium and relief of the abdominal distension. Two infants continued to have problems despite rectal washouts and became clinically obstructed with dilated bowel loops radiologically. Water soluble contrast enemas (Urografin 150, Schering Health Care Limited) were employed to relieve the obstruction (fig 2). In the first patient the enema revealed a microcolon with small meconium plugs in the distal colon and more compacted plugs in the proximal colon. Contrast medium could not be encouraged into the terminal ileum during the first enema, but at a second enema 24 hours later, contrast medium passed into dilated loops of terminal ileum containing meconium plugs. Large amounts of meconium were passed. In the second patient two water soluble contrast enemas were given over a 24 hour period. Multiple plugs of meconium plugs filled a normal calibre colon and distal ileum (fig 2). At the first attempt contrast medium did not pass beyond the terminal 


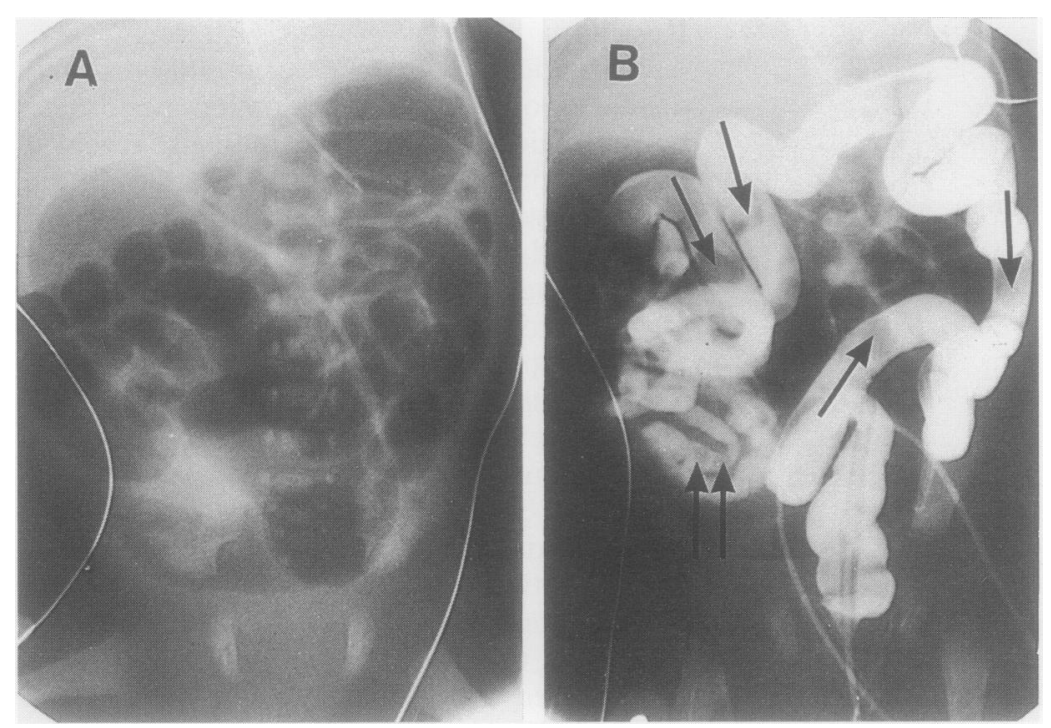

Figure 2 (A) Abdominal radiograph showing multiple dilated bowel loops. (B) Contrast study in same patient showing normal calibre colon and distal ileum containing multiple meconium plugs (arrowed).

ileum but did facilitate the passage of some meconium. The second enema revealed that much of the meconium had passed and contrast medium flowed beyond the meconium plugs into air-containing ileum.

In the control group, feeds were introduced at a median of 1 day with a range of 1-3 days. Two patients did not pass meconium within 24 hours of birth (27 and 34 hours) and three infants had mild abdominal distension but these symptoms responded to administration of glycerine suppositories and no baby required a rectal washout. Feeds were not interrupted.

Mean time to full enteral feeds and need for parenteral nutrition differed markedly between the FEG group and the controls. Full enteral feeds, defined as daily fluid requirement given enterally without the need for intravenous supplementation, were established by a median of 15 days in the FEG group with the range of 7-32 days, compared with a median of 4 days (range 1-8) in the control group (fig 3 ). Five of the infants in the FEG group required parenteral nutrition for a median of 15 days with a range of 5-27 days compared with one of the control group who required parenteral nutrition for four days only. The differences between the two groups in time to full enteral feeds and duration of parenteral nutrition were highly significant using Mann-Whitney $U$ analysis $(\mathrm{p}<0.01)$.

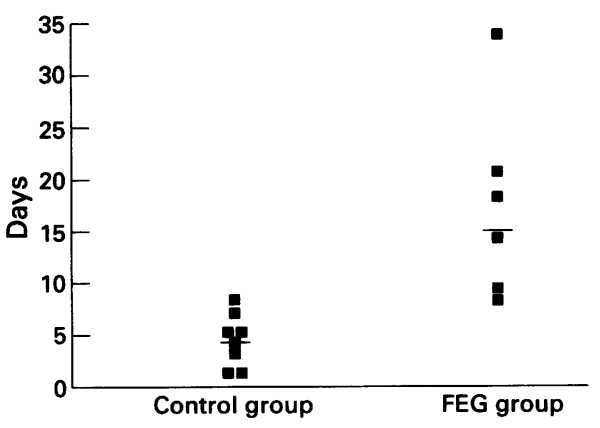

Figure 3 Time to full enteral feeds in FEG group and control group (Mann-Whitney $U$ analysis $p<0 \cdot 01$ ).
All infants subsequently tolerated feeds satisfactorily and had no further gastrointestinal problems during their stay on the neonatal unit. No infant developed necrotising enterocolitis and none of the infants had abnormal immune reactive trypsin or clinical features to suggest cystic fibrosis.

\section{Discussion}

There is now ample evidence to suggest that intrauterine growth retardation is strongly associated with increased perinatal mortality ${ }^{6}$ and neonatal morbidity ${ }^{7}$ and, in survivors, long term handicap. ${ }^{8}$

Doppler ultrasound technology has made it possible to study the flow characteristics of the fetal circulation and over the past decade many data have been reported that link reduced diastolic flow velocity in the umbilical artery with growth retardation. ${ }^{9-11}$ The abnormal flow velocity is associated with an obliteration of small arteries in the tertiary villi of the placenta, thus increasing the placental resistance. ${ }^{12}$ Comparison studies of Doppler velocities of the umbilical and carotid arteries of normal and growth retarded fetuses show a 'brain sparing' effect in the more compromised growth retarded group, ${ }^{13} 14$ suggesting a redistribution of regional blood flow in order to maintain optimal oxygen supply to the fetal brain. The beneficial effects of the relative increase in cerebral blood flow may be offset by a potentially detrimental effect on other vascular beds, including the splanchnic circulation.

Recent reports have also suggested an association between very abnormal umbilical artery Doppler studies which show absent or reversed end diastolic flow velocities and neonatal morbidity including an increased incidence of necrotising enterocolitis. ${ }^{45}$ This may be related to an ischaemic insult to the gut. Although intrauterine assessment of gut perfusion is technically very difficult it may be postulated that in the growth retarded fetus with abnormal end diastolic flow velocities the splanchnic circulation is compromised in favour of the cerebral circulation and in some cases it is possible that the gut may suffer from chronic hypoperfusion.

In the normal infant we have observed hyperechoic areas in the peritoneal cavity as a transient phenomenon during the second trimester. In infants with gastrointestinal problems, notably meconium peritonitis, hyperechogenicity due to calcification may be associated with intestinal distension or ascites. ${ }^{1}$ Hyperechogenic calcification has also been noted in congenital viral infection. The infants we describe had no evidence in utero of intestinal obstruction or ascites, no structural abnormalities of gut or chloaca, and no other associated anomalies. They shared the diagnostic triad of persistent generalised FEG, IUGR, and abnormal fetal Doppler studies. In these infants in which it was detected there was a difficulty in passing meconium, a delay in establishing full enteral feeds, increased need for parenteral nutrition and, in two cases, intestinal obstruction. Infants with FEG may 
be successfully managed with rectal washouts or, if necessary, water soluble contrast enemas. Noting the gut dysfunction in infants with FEG, we may speculate that FEG is a reflection of gut abnormality, perhaps ischaemia. This may occur as a result of redistribution of regional blood flow in the compromised fetus. This results in initial problems with passage of meconium and may adversely affect gut motility.

1 Foster MA, Nyberg DA, Mahony BS, Mack LA, Marks WM, Raabe RD. Meconium peritonitis: prenatal sonographic findings and their clinical significance. Radiology 1987; 165: 661-5.

2 Blott M, Greenough A, Gamsu HR, Nicolaides K, Campbell S. Antenatal factors associated with obstruction of the gastrointestinal tract by meconium. BMF 1988; 296: 250 .

3 Trudinger BJ, Giles WB, Cook CM, Bombardieri J, Collins L. Fetal umbilical artery flow velocity waveforms and placental resistance: clinical significance. $\mathrm{Br} \mathcal{F}$ Obstet Gynaecol 1985; 92: 23-30.

4 Malcolm G, Ellwood D, Devonald K, Beilby R, HendersonSmart D. Absent or reversed end diastolic flow velocity in the umbilical artery and necrotising enterocolitis. Arch Dis Child 1991; 66: 805-7.

5 Hackett GA, Campbell S, Gamsu H, Cohen-Overbeek T, Pearce JMF. Doppler studies in the growth retarded fetus and prediction of neonatal necrotising enterocolitis, haemorrhage, and neonatal morbidity. BMF 1987; 294:

6 Tejani N, Mann L. Diagnosis and management of the small for gestational age fetus. Clin Obstet Gynecol 1977; 20: 943-55.

7 Dobson PC, Abell DA, Beisher NA. Mortality and morbidity of fetal growth retardation. Aust N Z F Obstet Gynaecol 1981; 21: 69-72.

8 Commey JOO, Fitzhardinge PM. Handicap in the preterm small for gestational age infant. $\mathcal{f}$ Pediatr 1979; 94: 779-86.

9 Fleischer A, Shulman H, Farmakides G, Bracero L, Blattner $P$, Randolph G. Umbilical artery velocity waveforms and intrauterine growth retardation. Am $\mathcal{F}$ Obstet Gynecol intrauterine grow

10 Erskine RLA, Ritchie JWK. Umbilical artery blood flow characteristics in normal and growth retarded fetuses. $\mathrm{BrF}$ Obstet Gynaecol 1985; 92: 605-10.

11 Reuwer PJHM, Bruinse HW, Stoutenbeek P, Haspels AA. Doppler assessment of the feto-placental circulation in normal and growth retarded fetuses. Eur 7 Obstet Gynecol Reprod Biol 1984; 18: 199-205.

12 Giles WB, Trudinger BJ, Baird PJ. Fetal umbilical artery flow velocity waveforms and placental resistance: pathological correlation. Br $\mathcal{f}$ Obstet Gynaecol 1985; 92: pathol.

13 Wladimiroff JW, Noordam MJ, van den Wijngaard JAGW, Hop WCJ. Fetal internal carotid and umbilical artery blood flow velocity waveforms as a measure of fetal wellbeing in intrauterine growth retardation. Pediatr Res 1988; 24: 609-12.

14 Wladimiroff JW, van den Wijngaard JAGW, Degani $S$, Noordam MJ, van Eyck J, Tonge HM. Cerebral and umbilical arterial blood flow velocity waveforms in normal and growth-retarded pregnancies. Obstet Gynecol 1987; 69: 705-9. 